\title{
Influence of Preparation Process on Microstructure, Critical Current Density and $\mathrm{T}_{c}$ of $\mathrm{MgB}_{2} / \mathrm{Fe} / \mathrm{Cu}$ Wires
}

\author{
Y. F. Wu ${ }^{1} \dagger$, G. Yan ${ }^{1}$, J. S. Li $^{2}$, Y. Feng ${ }^{1}$, S. K. Chen ${ }^{1}$, H. P. Tang ${ }^{1}$, H. L. Xu ${ }^{3}$, \\ C. S. Li ${ }^{1}$, P. X. Zhang ${ }^{1}$, Y. F. Lu ${ }^{1}$ \\ ${ }^{1}$ Northwest Institute for Nonferrous Metal Research, P. O. Box 51, Xian, Shaanxi \\ 710016, P. R. China \\ ${ }^{2}$ Northwestern Polytechnical University, Xi'an 710012, P.R.China \\ ${ }^{3}$ School of Material Science and Engineering, Zhengzhou University, Zhengzhou, \\ Henan 450002, Peoples Republic of China
}

\begin{abstract}
The powder-in-tube $\mathrm{MgB}_{2}$ wires were prepared by high energy milling of $\mathrm{Mg}$ and $\mathrm{B}$ powder. The powder was not mechanically alloyed for $2 \mathrm{~h}$ short milling time. However, the $\mathrm{MgB}_{2}$ grains in wires are very small $(20100 \mathrm{~nm})$ and resembled to the dimple after post-heat treatment. The clear evidence for transcrystlline fracture is observed. It indicated that the grain connection was greatly improved and the fluxing pinning was significantly enhanced. Another point to view is no intermediate annealing was adopted during the whole rolling process. The influence of the post-heat treatment on the transport current density was studied. Despite the lower $\mathrm{T}_{c}$ of about $35 \mathrm{~K}$, the transport current density reaches to $3 \times 10^{4} \mathrm{~A} / \mathrm{cm}^{2}$ at $15 \mathrm{~K}$ and $3.5 \mathrm{~T}$ for $700^{\circ} \mathrm{c}$ sintered wires.
\end{abstract}

PACS numbers: 74.70.Ad, 74.62.Bf, 74.25.Qt, 74.25.Sv, 74.50.+r, 74.70.-b

$\dagger$ To whom correspondence should be addressed (wyf7777@tom.com) 
Influence of Preparation Process on Microstructure, Critical Current Density and $T_{c}$ of $\mathrm{MgB} / \mathrm{Fe} / \mathrm{Cu}$ Wires

\section{Introduction}

Preparation of $\mathrm{MgB}_{2}$ wires depends very critically on the precursor powder used for the powder-in-tube (PIT) techniques. Small grain sizes are favored preconditions for achieving high quality wires. Mechanical alloying (MA) technique for $\mathrm{MgB}_{2}$ powder preparation is expected for obtaining enhanced magnetic flux pinning by microstructure refinement. However, it costs as long as $20100 \mathrm{~h}[1,2,3-8]$ for in situ MA precursor powder preparation. The use of short-time unalloyed high energy milling of $\mathrm{Mg}$ and $\mathrm{B}$ powder as precursor material represents an efficient combination between conventional powder preparation and mechanical alloying techniques. Fe sheath was considered as one of suitable materials however hard it is. It is also gradually recognized that repeated annealing during rolling process would cause the inevitable diffusion of oxygen into the filament of $\mathrm{MgB}_{2}$ wire and decrease $\mathrm{J}_{c}$ greatly. Therefore, how to reduce intermediate annealing steps during material preparation become one of the biggest challenges as literatures[8-10] referred to.

\section{Experimental details}

$\operatorname{Mg}(99.8 \%)$ and amorphous B (95\%) powder with 5\% Mg surplus were filled under purified Ar-atmosphere into an agate milling container and milling media. The milling was performed on a SPEX $8000 \mathrm{M}$ mill for $2 \mathrm{~h}$ using a ball-to-powder mass ratio of 3. Monofilamentary wires were prepared by conventional PIT method. The powder was packed into coaxial $\mathrm{Cu} / \mathrm{Fe}$ tubes (outer diameter $14 \mathrm{~mm}$ and inner diameter $7 \mathrm{~mm}$ ) forming the billets. Next, billets were groove-rolled and drawn to a wire diameter of $1.2 \mathrm{~mm}$ without any intermediate annealing. The post heat treatment was performed at different temperatures for 1 hour under ultra-high purity Aratmosphere. The phase content of $\mathrm{MgB}_{2}$ was analysed by x-ray diffraction scans performed on a Philips APD1700 diffractometer with $\mathrm{Cu} \mathrm{K}$ radiation. The surface morphology and microstructures of the samples were characterized by JSM-6700F scanning electron microscope. The superconducting transition temperature, $\mathrm{T}_{c}$, was obtained by resistance-temperature method. The critical currents were evaluated from V-I curves taking a $1 \mathrm{~V} \mathrm{~cm} \mathrm{~cm}^{-1}$ criterion.

\section{Results and discussion}

As we know, the ductile deformation behavior at low temperatures is favored for acquiring high $\mathrm{J}_{c}$ performance $\mathrm{MgB}_{2}$ wires. In our study, no intermediate annealing was adopted during the whole rolling process. The total working modulus of Fe sheath exceeds 99 percent. A typical cross section for wire diameter of $1.2 \mathrm{~mm}$ is shown in figure 1. We concluded from our experience that the reduction in pass and rolling rate during rolling process should be controlled to a lower lever.

The microstructures of samples sintered at different temperatures are shown in 
Influence of Preparation Process on Microstructure, Critical Current Density and $T_{c}$ of $\mathrm{MgB} B_{2} / \mathrm{Fe} / \mathrm{Cu}$ Wires:

Fig.2. The Scanning electron microscope images mainly show dimple-like grains for $700800^{\circ} \mathrm{C}$ sintered samples. The grain sizes are about 20 100nm for $700^{\circ} \mathrm{C}$ and $750^{\circ} \mathrm{C}$ sintered samples. The clear evidence for the transcrystlline fracture is observed. It indicated that the grain connectivity was enhanced greatly. The grains are grown up to $100250 \mathrm{~nm}$ for $800^{\circ} \mathrm{C}$ sintered sample. While for $650^{\circ} \mathrm{C}$ reacted sample, large plate-like column crystals were observed. The impurity phases are evidently observed for sample sintered at $800^{\circ} \mathrm{C}$. Fig. 3 shows the wrap-around distribution of the second phases of the $800^{\circ} \mathrm{C}$ sintered sample. EDX analysis indicates that the bright one is O-rich zone and the grey one is Mg-rich zone, as seen in fig.4.

Fig. 5 indicates the superconducting transition $\mathrm{T}_{c}$ by resistance measurement for the samples sintered at different temperatures. As we can see, all samples have sharp transitions. $\mathrm{T}_{c}$ of the high energy milling samples ranged from 34.5 to $35.5 \mathrm{~K}$, which is much lower than $39 \mathrm{~K}$. Most likely, this is not due to a deviation from the ideal stoichiometry of the superconducting compound[2]. From x-ray analysis, interaction between the constituents of precursor powder and the sheath material can also be excluded. It seems that the suppression of $\mathrm{T}_{c}$ is caused by oxygen contamination in grain boundary induced by high energy milling as well as sintering process.

Fig.6 shows the $J_{c}$ - $B$ curve of the $\mathrm{MgB}_{2}$ wires at different temperatures. The critical currents were evaluated from V-I curves taking a $1 \mathrm{~V} \mathrm{~cm}^{-1}$ criterion. As we can see, the critical current densities are influenced greatly by heat treatment. The higher or lower heat treatment induced second phases and inferior microstructure, which led to bad grain connectivity and contribute to dramatic decrease of $J_{c}$. In the lower field, the $\mathrm{MgB}_{2}$ wires sintered at $700^{\circ} \mathrm{C}$ show the higher critical current density. In the higher field, the $\mathrm{MgB}_{2}$ wires sintered at $750^{\circ} \mathrm{C}$ show the higher critical current density. The critical current density reaches to $3 \times 10^{4} \mathrm{~A} / \mathrm{cm}^{2}$ at $15 \mathrm{~K}$ and $3.5 \mathrm{~T}$ for the wire sintered at $700^{\circ} \mathrm{C}$.

In Summary, we succeeded in preparing high critical current density $\mathrm{MgB}_{2}$ wire using unalloyed high energy milling precursor powder. The powder preparation process was greatly shortened. It demonstrated that it is an effective approach to get fine crystalline $\mathrm{MgB}_{2}$ with good grain connectivity and high $J_{c}$ performance. The critical current density reaches to $3 \times 10^{4} \mathrm{~A} / \mathrm{cm}^{2}$ at $15 \mathrm{~K}$ and $3.5 \mathrm{~T}$ for the wire sintered at $700^{\circ} \mathrm{c}$.

\section{Acknowledge}

This work was partially supported by National Natural Science Foundation project (contract No. 50472099) and National Basic Research Program of China (contract No. 2006CB601004). 
Influence of Preparation Process on Microstructure, Critical Current Density and $T_{c}$ of $\mathrm{MgB} / \mathrm{Fe} / \mathrm{Cu}$ Wires

\section{References}

[1] V.N. Narozhnyi, G. Fuchs, A, Handstein, A. Gumbel, J. Eckert, K. Nenkov, D. Hinz, O. Gutfleisch, A. Walte, L. N. Bogacheva, I. E. Kostyleva, K.-H. Muller, L. Schultz, Int. Conf. on Superconductivity, CMR \& Related Materials: Novel Trends (SCRM2002), Giens, France, 1-8 June 2002.

[2] A. Gumbel, O. Perner, J. Eckert, G. Fuchs, K. Nenkov, K.-H. Muller, and L. Schultz, IEEE TRANSACTIONS ON APPLIED SUPERCONDUCTIVITY, Vol. 13, No. 2, JUNE 2003.

[3] A. Gumbel, J. Eckert, G. Fuchs, K. Nenkov, K.-H. Muller and L. Schultz, APPLIED PHYSICS LETTERS, Vol. 80, No. 15, 15 APRIL 2002, pp.2725-2727.

[4] W. Haler, C. Roding, C. Fischer, B. Holzapfel, O. Perner, J. Eckert, K. Nenkov and G. Fuchs, Supercond. Sci. Technol. 16 (2003) pp.281-284.

[5] C. Fischer, C. Roding, W. Haler, O. Perner, J. Eckert, K. Nenkov, G. Fuchs, H. Wendrock, B. Holzapfel and L. Schultz, APPLIED PHYSICS LETTERS, Vol. 83, No. 9, 1 SEPTEMBER 2003, pp.1803-1805.

[6] O. Perner, J. Eckert, W. Haler, C. Fischer, K-H Muller, G. Fuchs, B Holzapfel and L Schultz, Supercond. Sci. Technol. 17 (2004) pp.1148-1153.

[7] Olaf Perner, Wolfgang Haler, Claus Fischer, Gunter Fuchs, Bernhard Holzapfel, Ludwig Schultz and Jurgen Eckert, IEEE TRANSACTIONS ON APPLIED SUPERCONDUCTIVITY, VOL. 15, NO. 2, JUNE 2005.

[8] O. Perner, J. Eckert, W. Haler, C. Fischer, J. Acker, T. Gemming, G. Fuchs, B. Holzapfel and L. Schultz, JOURNAL OF APPLIED PHYSICS 97, 056105(2005), pp.1-3.

[9] C. Buzea and T. Yamashita, Supercond. Sci. Technol. 14, R 115 (2001).

[10] V. N. Narozhnyi, G. Fuchs, A. Handstein, A. Gmbel, J. Eckert, K. Nenkov, D. Hinz, O. Gutfleisch, A. W?lte, L. N. Bogacheva, I. E. Kostyleva, K.-H. Mller, and L. Schultz, J. Supercond. 15, 599 (2002) 
Influence of Preparation Process on Microstructure, Critical Current Density and $T_{c}$ of $\mathrm{MgB} B_{2} / \mathrm{Fe} / \mathrm{Cu}$ Wires:

Figure captions

Fig. 1 A typical cross section for wire diameter of $1.2 \mathrm{~mm}$.

Fig.2 The Scanning electron microscope images of samples sintered at different temperatures: (a) $650{ }^{\circ} \mathrm{c}$; (b) $700^{\circ} \mathrm{c}$; (c) $750{ }^{\circ} \mathrm{C}$ and (d) $800^{\circ} \mathrm{C}$.

Fig.3 The wrap-around distribution of the second phases for $800^{\circ} \mathrm{C}$ sintered $\mathrm{MgB}_{2}$ wires.

Fig.4 The EDX analysis of the second phases for $800^{\circ} \mathrm{C}$ sintered $\mathrm{MgB}_{2}$ wires. It shows: (a) the bright one is O-rich zone; (b) the grey one is Mg-rich zone.

Fig.5 Superconducting transition $\mathrm{T}_{c}$ by resistance measurement for the samples sintered at different temperatures.

Fig.6 Transport $J_{c}-B$ curve of the $\mathrm{MgB}_{2}$ wires at different temperatures. 
Influence of Preparation Process on Microstructure, Critical Current Density and $T_{c}$ of $M g B_{2} / \mathrm{Fe} / \mathrm{Cu}$ Wires Fig.1

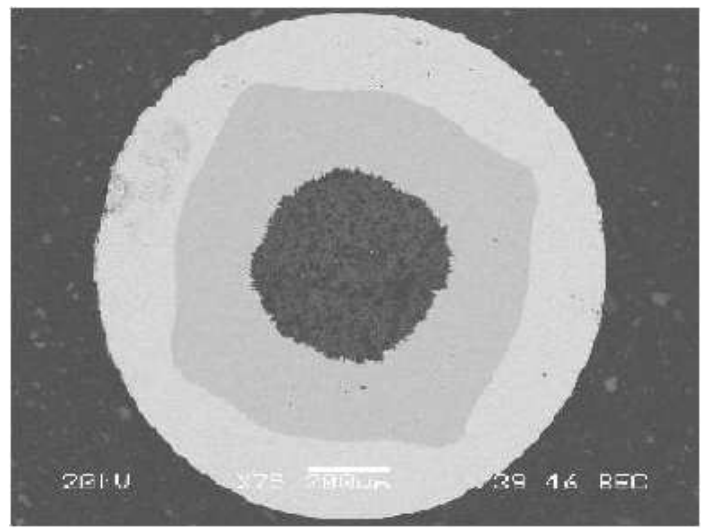


Influence of Preparation Process on Microstructure, Critical Current Density and $T_{c}$ of $\mathrm{MgB} / \mathrm{Fe} / \mathrm{Cu}$ Wires Fig.2

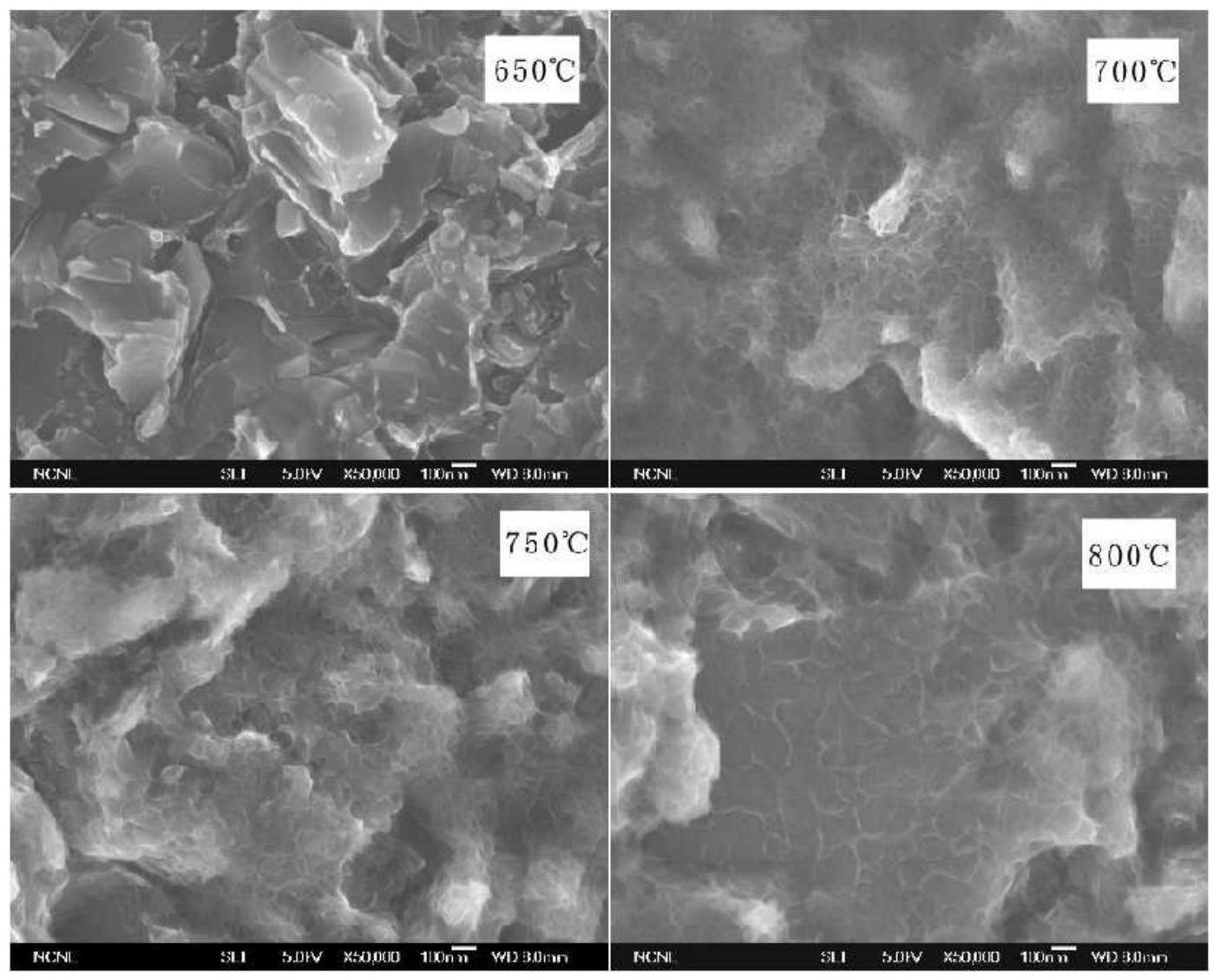


Influence of Preparation Process on Microstructure, Critical Current Density and $T_{c}$ of $\mathrm{MgB} / \mathrm{Fe} / \mathrm{Cu}$ Wires Fig.3

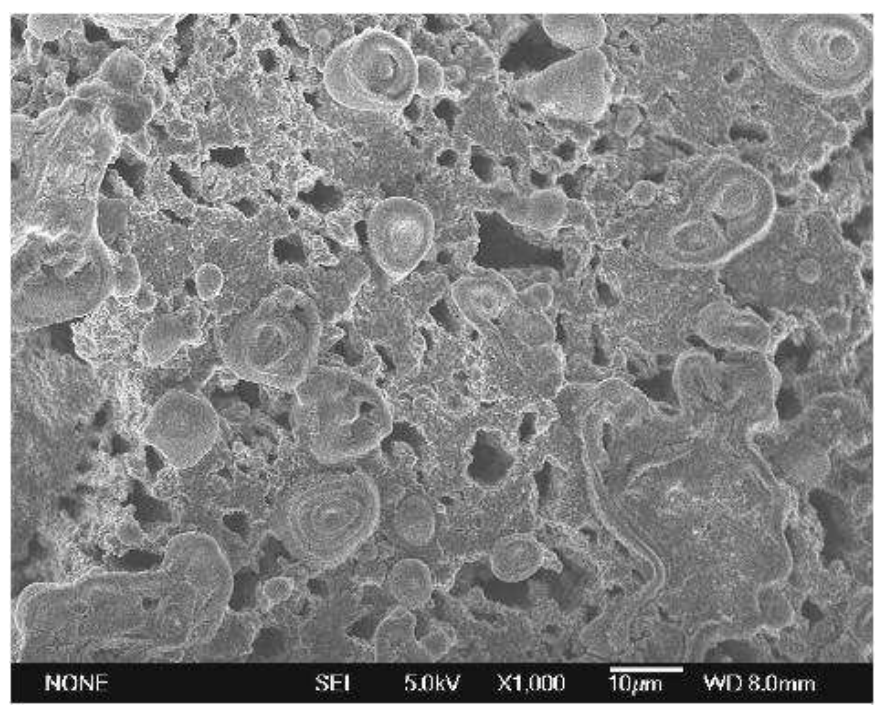


Influence of Preparation Process on Microstructure, Critical Current Density and $T_{c}$ of $M g B_{2} / \mathrm{Fe} / \mathrm{Cu}$ Wires Fig.4
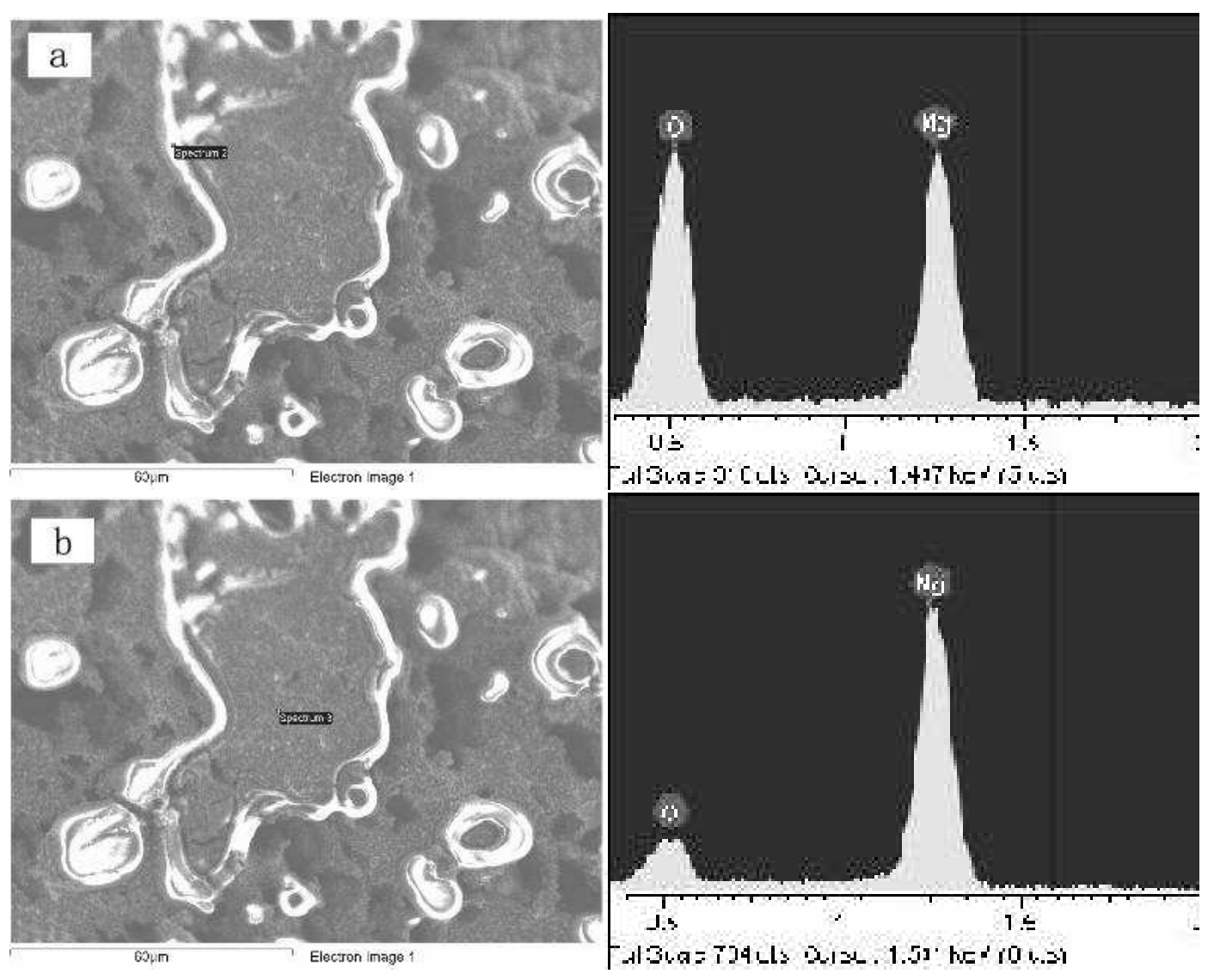
Influence of Preparation Process on Microstructure, Critical Current Density and $T_{c}$ of $\mathrm{MgB} / \mathrm{Fe} / \mathrm{Cu}$ Wires Fig.5

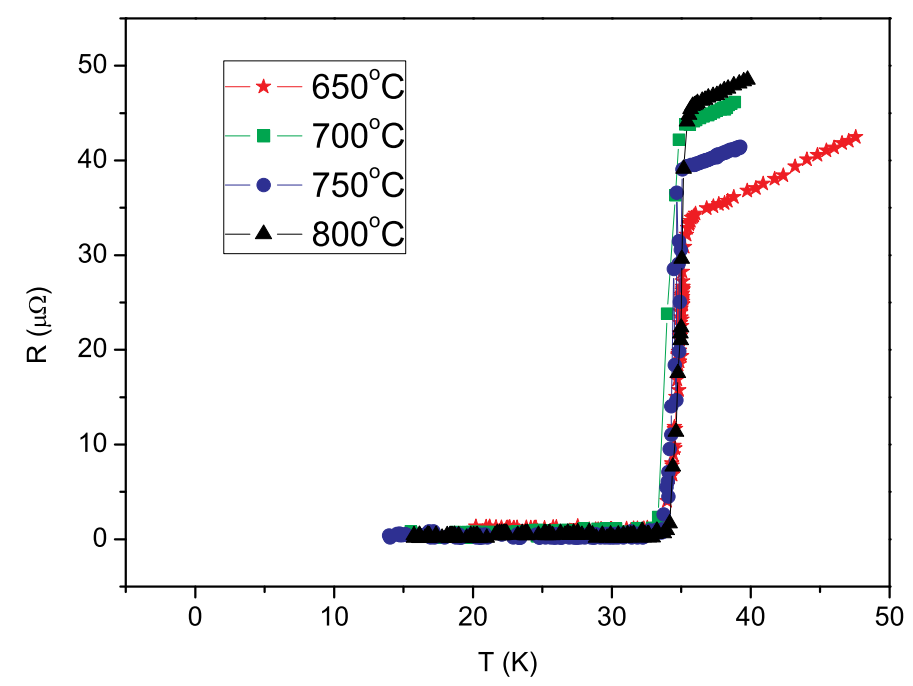


Influence of Preparation Process on Microstructure, Critical Current Density and $T_{c}$ of $\mathrm{MgB} / \mathrm{Fe} / \mathrm{Cu}$ Wires Fig.6

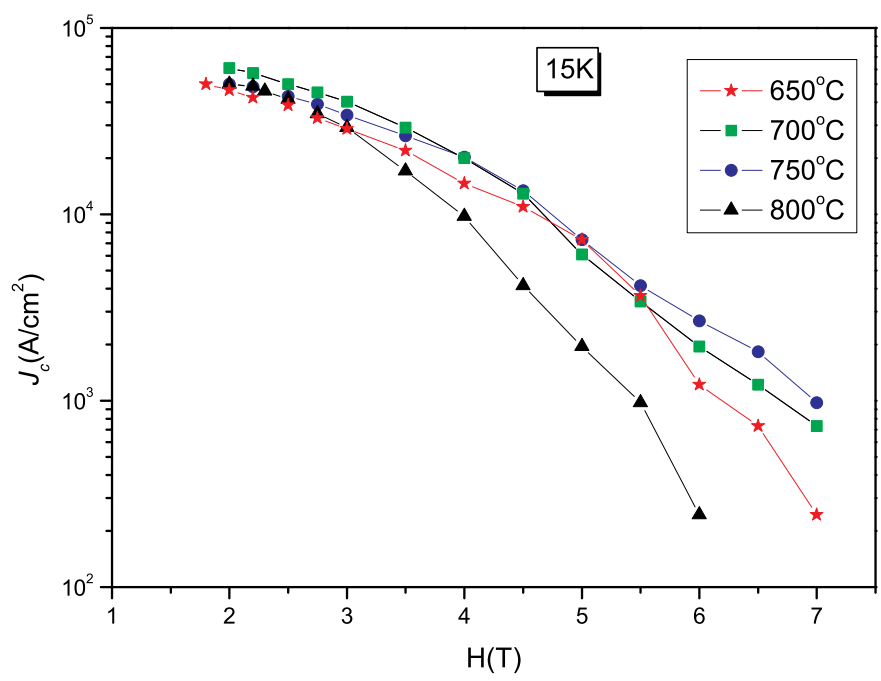




\title{
Influence of Preparation Process on Microstructure, Critical Current Density and $\mathrm{T}_{c}$ of $\mathrm{MgB}_{2} / \mathrm{Fe} / \mathrm{Cu}$ Wires
}

\author{
Y. F. Wu ${ }^{1} \dagger$, G. Yan ${ }^{1}$, J. S. Li $^{2}$, Y. Feng ${ }^{1}$, S. K. Chen ${ }^{1}$, H. P. Tang ${ }^{1}$, H. L. Xu ${ }^{3}$, \\ C. S. Li ${ }^{1}$, P. X. Zhang ${ }^{1}$, Y. F. Lu ${ }^{1}$ \\ ${ }^{1}$ Northwest Institute for Nonferrous Metal Research, P. O. Box 51, Xian, Shaanxi \\ 710016, P. R. China \\ ${ }^{2}$ Northwestern Polytechnical University, Xi'an 710012, P.R.China \\ ${ }^{3}$ School of Material Science and Engineering, Zhengzhou University, Zhengzhou, \\ Henan 450002, Peoples Republic of China
}

\begin{abstract}
The powder-in-tube $\mathrm{MgB}_{2}$ wires were prepared by high energy milling of $\mathrm{Mg}$ and $\mathrm{B}$ powder. The powder was not mechanically alloyed for $2 \mathrm{~h}$ short milling time. However, the $\mathrm{MgB}_{2}$ grains in wires are very small $(20100 \mathrm{~nm})$ and resembled to the dimple after post-heat treatment. The clear evidence for transcrystlline fracture is observed. It indicated that the grain connection was greatly improved and the fluxing pinning was significantly enhanced. Another point to view is no intermediate annealing was adopted during the whole rolling process. The influence of the post-heat treatment on the transport current density was studied. Despite the lower $\mathrm{T}_{c}$ of about $35 \mathrm{~K}$, the transport current density reaches to $3 \times 10^{4} \mathrm{~A} / \mathrm{cm}^{2}$ at $15 \mathrm{~K}$ and $3.5 \mathrm{~T}$ for $700^{\circ} \mathrm{c}$ sintered wires.
\end{abstract}

PACS numbers: 74.70.Ad, 74.62.Bf, 74.25.Qt, 74.25.Sv, 74.50.+r, 74.70.-b

$\dagger$ To whom correspondence should be addressed (wyf7777@tom.com) 
Influence of Preparation Process on Microstructure, Critical Current Density and $T_{c}$ of $\mathrm{MgB} / \mathrm{Fe} / \mathrm{Cu}$ Wires

\section{Introduction}

Preparation of $\mathrm{MgB}_{2}$ wires depends very critically on the precursor powder used for the powder-in-tube (PIT) techniques. Small grain sizes are favored preconditions for achieving high quality wires. Mechanical alloying (MA) technique for $\mathrm{MgB}_{2}$ powder preparation is expected for obtaining enhanced magnetic flux pinning by microstructure refinement. However, it costs as long as $20100 \mathrm{~h}[1,2,3-8]$ for in situ MA precursor powder preparation. The use of short-time unalloyed high energy milling of $\mathrm{Mg}$ and $\mathrm{B}$ powder as precursor material represents an efficient combination between conventional powder preparation and mechanical alloying techniques. Fe sheath was considered as one of suitable materials however hard it is. It is also gradually recognized that repeated annealing during rolling process would cause the inevitable diffusion of oxygen into the filament of $\mathrm{MgB}_{2}$ wire and decrease $\mathrm{J}_{c}$ greatly. Therefore, how to reduce intermediate annealing steps during material preparation become one of the biggest challenges as literatures[8-10] referred to.

\section{Experimental details}

$\operatorname{Mg}(99.8 \%)$ and amorphous B (95\%) powder with 5\% Mg surplus were filled under purified Ar-atmosphere into an agate milling container and milling media. The milling was performed on a SPEX $8000 \mathrm{M}$ mill for $2 \mathrm{~h}$ using a ball-to-powder mass ratio of 3. Monofilamentary wires were prepared by conventional PIT method. The powder was packed into coaxial $\mathrm{Cu} / \mathrm{Fe}$ tubes (outer diameter $14 \mathrm{~mm}$ and inner diameter $7 \mathrm{~mm}$ ) forming the billets. Next, billets were groove-rolled and drawn to a wire diameter of $1.2 \mathrm{~mm}$ without any intermediate annealing. The post heat treatment was performed at different temperatures for 1 hour under ultra-high purity Aratmosphere. The phase content of $\mathrm{MgB}_{2}$ was analysed by x-ray diffraction scans performed on a Philips APD1700 diffractometer with $\mathrm{Cu} \mathrm{K}$ radiation. The surface morphology and microstructures of the samples were characterized by JSM-6700F scanning electron microscope. The superconducting transition temperature, $\mathrm{T}_{c}$, was obtained by resistance-temperature method. The critical currents were evaluated from V-I curves taking a $1 \mathrm{~V} \mathrm{~cm} \mathrm{~cm}^{-1}$ criterion.

\section{Results and discussion}

As we know, the ductile deformation behavior at low temperatures is favored for acquiring high $\mathrm{J}_{c}$ performance $\mathrm{MgB}_{2}$ wires. In our study, no intermediate annealing was adopted during the whole rolling process. The total working modulus of Fe sheath exceeds 99 percent. A typical cross section for wire diameter of $1.2 \mathrm{~mm}$ is shown in figure 1. We concluded from our experience that the reduction in pass and rolling rate during rolling process should be controlled to a lower lever.

The microstructures of samples sintered at different temperatures are shown in 
Influence of Preparation Process on Microstructure, Critical Current Density and $T_{c}$ of $\mathrm{MgB} / \mathrm{Fe} / \mathrm{Cu}$ Wires

Fig.2. The Scanning electron microscope images mainly show dimple-like grains for $700800^{\circ} \mathrm{C}$ sintered samples. The grain sizes are about $20 \quad 100 \mathrm{~nm}$ for $700{ }^{\circ} \mathrm{C}$ and $750{ }^{\circ} \mathrm{C}$ sintered samples. The clear evidence for the transcrystlline fracture is observed. It indicated that the grain connectivity was enhanced greatly. The grains are grown up to $100250 \mathrm{~nm}$ for $800^{\circ} \mathrm{C}$ sintered sample. While for $650^{\circ} \mathrm{c}$ reacted sample, large plate-like column crystals were observed. The impurity phases are evidently observed for sample sintered at $800^{\circ} \mathrm{C}$. Fig.3 shows the wrap-around distribution of the second phases of the $800^{\circ} \mathrm{C}$ sintered sample. EDX analysis indicates that the bright one is O-rich zone and the grey one is Mg-rich zone, as seen in fig.4.

Fig. 5 indicates the superconducting transition $\mathrm{T}_{c}$ by resistance measurement for the samples sintered at different temperatures. As we can see, all samples have sharp transitions. $\mathrm{T}_{c}$ of the high energy milling samples ranged from 34.5 to $35.5 \mathrm{~K}$, which is much lower than 39K. Most likely, this is not due to a deviation from the ideal stoichiometry of the superconducting compound[2]. From x-ray analysis, interaction between the constituents of precursor powder and the sheath material can also be excluded. It seems that the suppression of $\mathrm{T}_{c}$ is caused by oxygen contamination in grain boundary induced by high energy milling as well as sintering process.

Fig. 6 shows the $J_{c}-B$ curve of the $\mathrm{MgB}_{2}$ wires at different temperatures. The critical currents were evaluated from $\mathrm{V}$-I curves taking a $1 \mathrm{~V} \mathrm{~cm}^{-1}$ criterion. As we can see, the critical current densities are influenced greatly by heat treatment. The higher or lower heat treatment induced second phases and inferior microstructure, which led to bad grain connectivity and contribute to dramatic decrease of $J_{c}$. In the lower field, the $\mathrm{MgB}_{2}$ wires sintered at $700^{\circ} \mathrm{C}$ show the higher critical current density. In the higher field, the $\mathrm{MgB}_{2}$ wires sintered at $750^{\circ} \mathrm{C}$ show the higher critical current density. The critical current density reaches to $3 \times 10^{4} \mathrm{~A} / \mathrm{cm}^{2}$ at $15 \mathrm{~K}$ and $3.5 \mathrm{~T}$ for the wire sintered at $700^{\circ} \mathrm{C}$.

In Summary, we succeeded in preparing high critical current density $\mathrm{MgB}_{2}$ wire using unalloyed high energy milling precursor powder. The powder preparation process was greatly shortened. It demonstrated that it is an effective approach to get fine crystalline $\mathrm{MgB}_{2}$ with good grain connectivity and high $J_{c}$ performance. The critical current density reaches to $3 \times 10^{4} \mathrm{~A} / \mathrm{cm}^{2}$ at $15 \mathrm{~K}$ and $3.5 \mathrm{~T}$ for the wire sintered at $700{ }^{\circ} \mathrm{c}$.

\section{Acknowledge}

This work was partially supported by National Natural Science Foundation project (contract No. 50472099) and National Basic Research Program of China (contract No. 2006CB601004). 
Influence of Preparation Process on Microstructure, Critical Current Density and $T_{c}$ of $\mathrm{MgB} / \mathrm{Fe} / \mathrm{Cu}$ Wires

\section{References}

[1] V.N. Narozhnyi, G. Fuchs, A, Handstein, A. Gumbel, J. Eckert, K. Nenkov, D. Hinz, O. Gutfleisch, A. Walte, L. N. Bogacheva, I. E. Kostyleva, K.-H. Muller, L. Schultz, Int. Conf. on Superconductivity, CMR \& Related Materials: Novel Trends (SCRM2002), Giens, France, 1-8 June 2002.

[2] A. Gumbel, O. Perner, J. Eckert, G. Fuchs, K. Nenkov, K.-H. Muller, and L. Schultz, IEEE TRANSACTIONS ON APPLIED SUPERCONDUCTIVITY, Vol. 13, No. 2, JUNE 2003.

[3] A. Gumbel, J. Eckert, G. Fuchs, K. Nenkov, K.-H. Muller and L. Schultz, APPLIED PHYSICS LETTERS, Vol. 80, No. 15, 15 APRIL 2002, pp.2725-2727.

[4] W. Haler, C. Roding, C. Fischer, B. Holzapfel, O. Perner, J. Eckert, K. Nenkov and G. Fuchs, Supercond. Sci. Technol. 16 (2003) pp.281-284.

[5] C. Fischer, C. Roding, W. Haler, O. Perner, J. Eckert, K. Nenkov, G. Fuchs, H. Wendrock, B. Holzapfel and L. Schultz, APPLIED PHYSICS LETTERS, Vol. 83, No. 9, 1 SEPTEMBER 2003, pp.1803-1805.

[6] O. Perner, J. Eckert, W. Haler, C. Fischer, K-H Muller, G. Fuchs, B Holzapfel and L Schultz, Supercond. Sci. Technol. 17 (2004) pp.1148-1153.

[7] Olaf Perner, Wolfgang Haler, Claus Fischer, Gunter Fuchs, Bernhard Holzapfel, Ludwig Schultz and Jurgen Eckert, IEEE TRANSACTIONS ON APPLIED SUPERCONDUCTIVITY, VOL. 15, NO. 2, JUNE 2005.

[8] O. Perner, J. Eckert, W. Haler, C. Fischer, J. Acker, T. Gemming, G. Fuchs, B. Holzapfel and L. Schultz, JOURNAL OF APPLIED PHYSICS 97, 056105(2005), pp.1-3.

[9] C. Buzea and T. Yamashita, Supercond. Sci. Technol. 14, R 115 (2001).

[10] V. N. Narozhnyi, G. Fuchs, A. Handstein, A. Gmbel, J. Eckert, K. Nenkov, D. Hinz, O. Gutfleisch, A. W?lte, L. N. Bogacheva, I. E. Kostyleva, K.-H. Mller, and L. Schultz, J. Supercond. 15, 599 (2002) 
Influence of Preparation Process on Microstructure, Critical Current Density and $T_{c}$ of $\mathrm{MgB} / \mathrm{Fe} / \mathrm{Cu}$ Wires

\section{Figure captions}

Fig. 1 A typical cross section for wire diameter of $1.2 \mathrm{~mm}$.

Fig.2 The Scanning electron microscope images of samples sintered at different temperatures: (a) $650^{\circ} \mathrm{c}$; (b) $700^{\circ} \mathrm{c}$; (c) $750{ }^{\circ} \mathrm{C}$ and (d) $800^{\circ} \mathrm{C}$.

Fig.3 The wrap-around distribution of the second phases for $800^{\circ} \mathrm{C}$ sintered $\mathrm{MgB}_{2}$ wires.

Fig. 4 The EDX analysis of the second phases for $800^{\circ} \mathrm{C}$ sintered $\mathrm{MgB}_{2}$ wires. It shows: (a) the bright one is O-rich zone; (b) the grey one is Mg-rich zone.

Fig.5 Superconducting transition $\mathrm{T}_{c}$ by resistance measurement for the samples sintered at different temperatures.

Fig.6 Transport $J_{c}-B$ curve of the $\mathrm{MgB}_{2}$ wires at different temperatures. 
Influence of Preparation Process on Microstructure, Critical Current Density and $T_{c}$ of $\mathrm{MgB} / \mathrm{Fe} / \mathrm{Cu}$ Wires

Fig.1

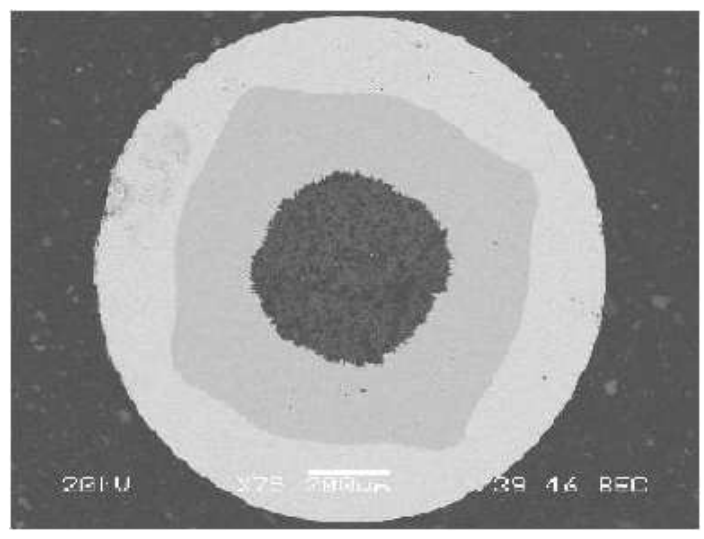


Influence of Preparation Process on Microstructure, Critical Current Density and $T_{c}$ of $\mathrm{MgB} / \mathrm{Fe} / \mathrm{Cu}$ Wires

Fig.2

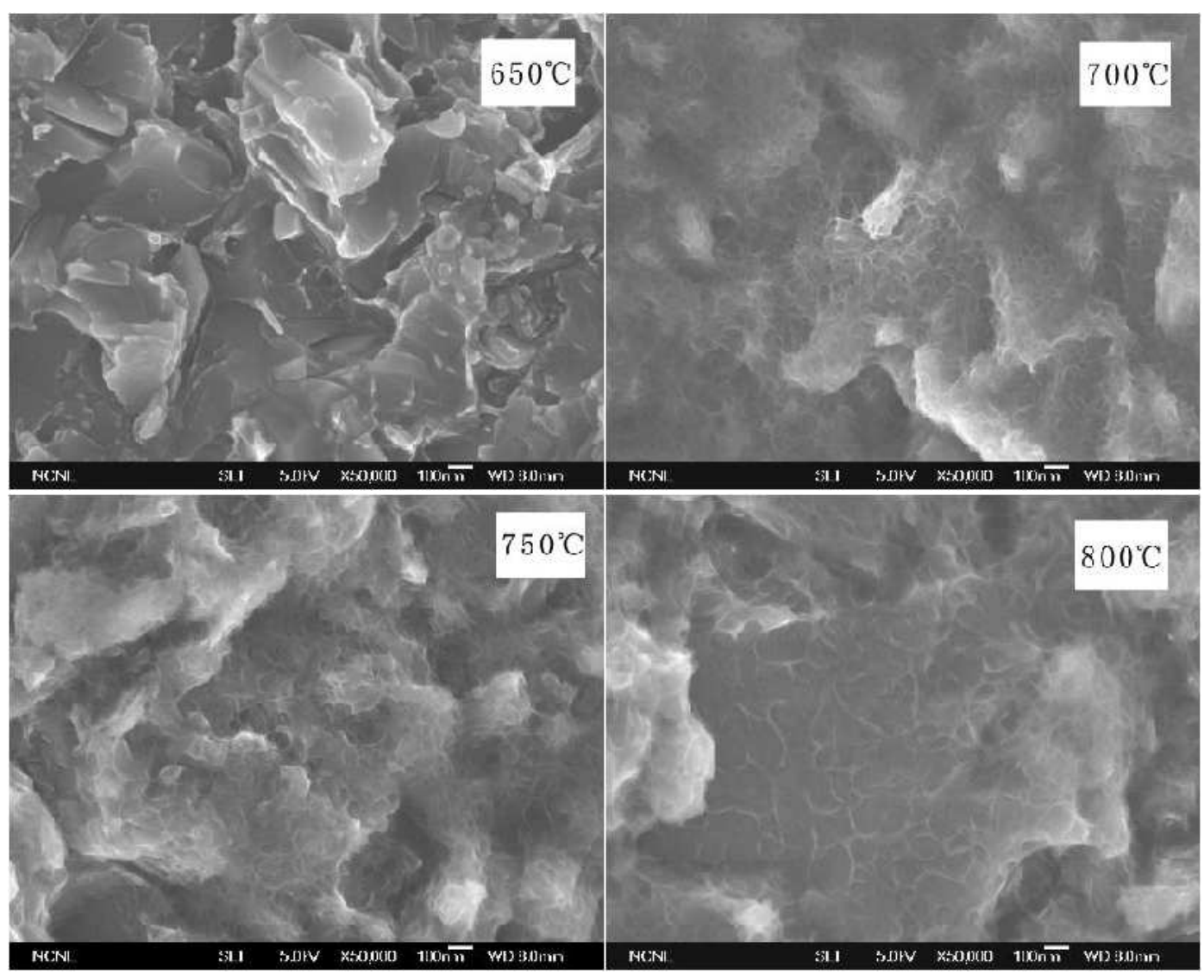


Influence of Preparation Process on Microstructure, Critical Current Density and $T_{c}$ of $\mathrm{MgB} / \mathrm{Fe} / \mathrm{Cu}$ Wires

Fig.3

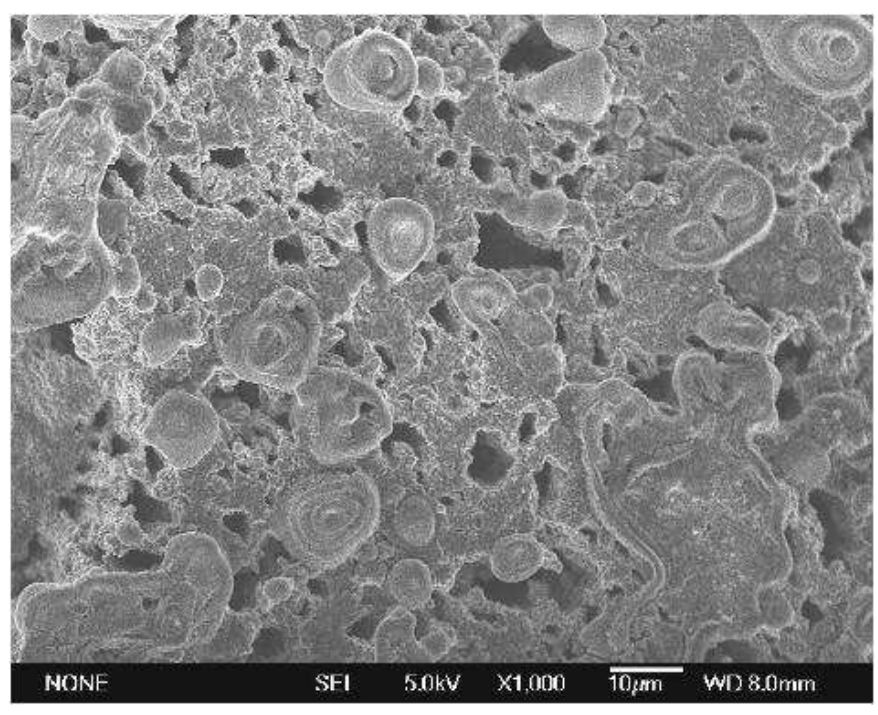


Influence of Preparation Process on Microstructure, Critical Current Density and $T_{c}$ of $\mathrm{MgB} / \mathrm{Fe} / \mathrm{Cu}$ Wires

Fig.4

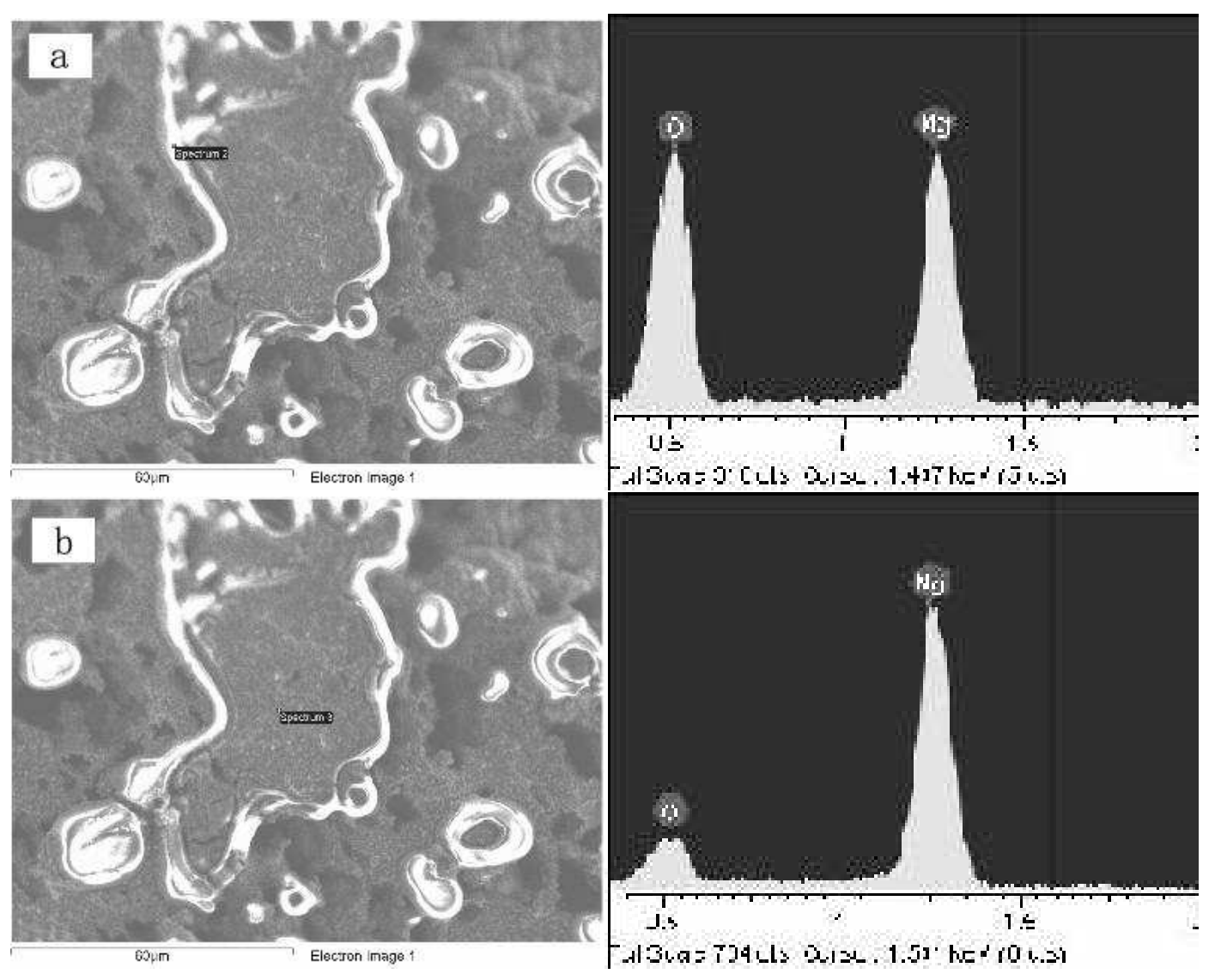


Influence of Preparation Process on Microstructure, Critical Current Density and $T_{c}$ of $\mathrm{MgB} \mathrm{B}_{2} / \mathrm{Fe} / \mathrm{Cu}$ Wires

Fig.5

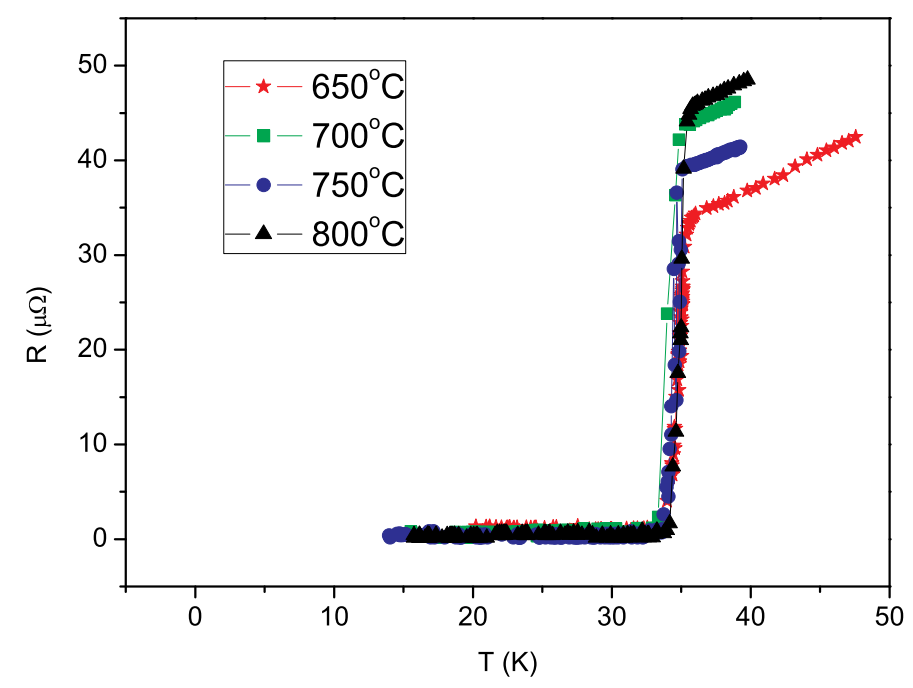


Influence of Preparation Process on Microstructure, Critical Current Density and $T_{c}$ of $\mathrm{MgB} / \mathrm{Fe} / \mathrm{Cu}$ Wires

Fig.6

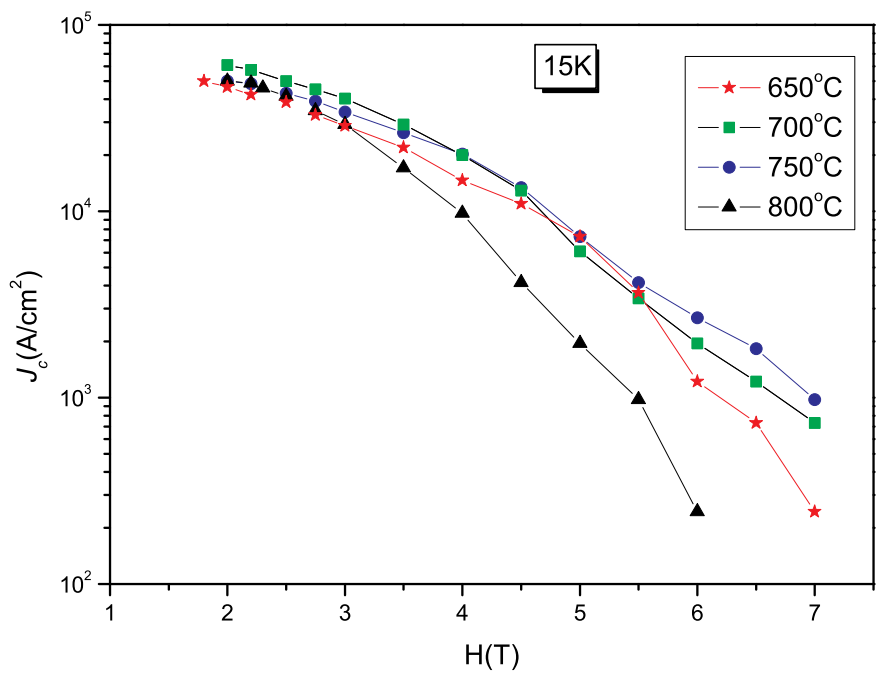

